\title{
Rezension: Moritz Oehen, Der Strafkläger im Strafbefehls- und im abgekürzten Verfahren
}

\section{Christina Galeazzi *}

Die schweizerische Strafprozessordnung erlaubt es einer geschädigten Person, sich als Partei am Strafverfahren zu beteiligen, sofern sie sich als Zivil- und/oder Strafkläger konstituiert (Art. 104 Abs. 1 lit. b i.V.m. Art. 118 Abs. 1 StPO). Der Zivilkläger war vor Inkrafttreten der schweizerischen Strafprozessordnung bereits auf kantonaler Ebene gesetzlich verankert. Dagegen war die Figur des Strafklägers einzig in der Verfahrensordnung des Kantons Bern zu finden. Der eidgenössische Gesetzgeber war beim Erlass der Strafprozessordnung um eine effiziente Ausgestaltung des Strafverfahrens bemüht. Als Beispiele lassen sich hierfür etwa die Ausweitung des Anwendungsbereichs des Strafbefehlsverfahrens oder die Einführung des abgekürzten Verfahrens nennen. Die gesetzgeberischen Effizienzbestrebungen und ihre (Un-)vereinbarkeit mit den Rechten der beschuldigten Person sind Gegenstand anhaltender Diskussionen. Dagegen steht bei Oehen nicht die beschuldigte Person im Fokus, stattdessen konzentriert er sich in seiner Dissertation auf den Strafkläger. Er geht der Frage nach, ob die schweizerische Strafprozessordnung einen effizienten und gleichzeitig einen aus Sicht des Strafklägers geschädigtenfreundlichen Strafprozess, namentlich in Form des Strafbefehls- und des abgekürzten Verfahrens, erlaubt.

Zitiervorschlag: Christina Galeazzi, Rezension: Moritz Oehen, Der Strafkläger im Strafbefehls- und im abgekürzten Verfahren, in: sui-generis 2020, S. 34

URL: sui-generis.ch/119

DOI: https://doi.org/10.21257/sg.119

* Dr. Christina Galeazzi, Rechtsanwältin, Litigation Counsel UBS (ch_galeazzi@hotmail.com). 
1 Oehen beginnt einleitend (Kapitel 1) mit einem Abriss zur Entwicklung des Strafklägers in der Schweiz und stellt fest, dass die Aufnahme der Figur des Strafklägers in der schweizerischen Strafprozessordnung eine «Rechtswohltat» ist (S. 18 ff.). Denn das Recht, sich als Strafkläger zu konstituieren, lässt sich einzig aus der Strafprozessordnung selbst und nicht etwa aus übergeordnetem Völkeroder Verfassungsrecht ableiten. Nur ausnahmsweise besteht für Opfer ein konventionsrechtlicher Anspruch auf Konstituierung als Strafkläger. Unbeantwortet bleibt die Frage, weshalb der Gesetzgeber nach dem Vorbild des Kantons Bern die Figur des Strafklägers in die schweizerische Strafprozessordnung aufgenommen hat.

Unter dem Titel «Die Teilhabe des Strafklägers» befasst sich Oehen in Kapitel 2 mit der Konstituierung des Strafklägers (S. $23 \mathrm{ff}$.) sowie seinen Verfahrensrechten im ordentlichen Strafverfahren (S. 41 ff.). Die Erläuterungen zur Konstituierung des Strafklägers fallen mit dem Hinweis auf ihre Funktion als eigentliches Eintrittsticket ins Strafverfahren ausführlich aus.

Mit der Konstituierung als Strafkläger kommt der geschädigten Person Parteistellung zu. Da die strafklägerischen Verfahrensrechte auf die zur Wahrung der geschützten Interessen notwendigen Rechte beschränkt sind, legt Oehen zunächst dar, was unter den rechtlich geschützten Interessen des Strafklägers zu verstehen ist (S. $41 \mathrm{ff}$.): Gemäss Art. 119 Abs. 2 lit. a StPO kann der Strafkläger die Verfolgung und Bestrafung der für die Straftat verantwortlichen Person verlangen. Oehen zeigt auf, dass in Art. 119
Abs. 2 lit. a StPO Bestrafung als Verurteilung zu verstehen ist. Folglich besteht nach Oehen das rechtlich geschützte Interesse des Strafklägers darin, die Verfolgung und Verurteilung der für die Straftat verantwortlichen Person verlangen zu können. Rechtlich nicht geschützt sind dagegen etwaige (faktische) Interessen des Strafklägers an der auszusprechenden Strafe.

4 In den nachfolgenden Untersuchungen zu den einzelnen Verfahrensrechten stellt Oehen fest, dass der Strafkläger im ordentlichen Verfahren mit der beschuldigten Person weitgehend auf Augenhöhe steht. Eine Benachteiligung gegenüber dem Beschuldigten und insbesondere gegenüber dem Zivilkläger sieht Oehen bei der unentgeltlichen Rechtspflege, welche dem Strafkläger nur unter sehr eingeschränkten Bedingungen gewährt wird (S. 69 ff.) und bei der Parteientschädigung (S. 86 ff.). Für Letztere haftet - soweit eine solche zugesprochen wird einzig die beschuldigte Person. Eine subsidiäre Entschädigungspflicht des Staates gibt es nicht. $\mathrm{Ob}$ eine solche subsidiäre Entschädigungspflicht des Staates tatsächlich zu fordern bzw. wünschenswert ist, bleibt meines Erachtens jedoch fraglich.

5 Mit Blick auf die eingangs gestellte Frage bilden Kapitel 3 bis 5 die Kernstücke der Arbeit:

6 Kapitel 3 behandelt den Strafkläger im Strafbefehlsverfahren, wobei die Phase vor und diejenige nach Strafbefehlserlass voneinander zu unterscheiden sind. Für die Phase nach Strafbefehlserlass scheiterte der gesetzgeberische Versuch, die Stellung des Strafklägers zwecks Effizienz- 
steigerung über die fehlende Einsprachelegitimation zu schwächen (S. 106 ff.). Nach höchstrichterlicher Rechtsprechung kann nämlich auch der Strafkläger gegen einen Strafbefehl Einsprache erheben. Mit der laufenden Revision der Strafprozessordnung soll dies im Gesetz auch entsprechend geändert werden. Dagegen kommt Oehen zum Ergebnis, dass der Strafkläger in der Phase vor Strafbefehlserlass nur sehr eingeschränkt auf das Verfahren Einfluss nehmen kann. Dies zeigt sich u.a. daran, dass beispielsweise im Kanton Zürich Strafbefehle erlassen werden, selbst wenn sich die geschädigte Person noch nicht zu ihrer Konstituierung äussern konnte (S. 96 ff.). Zwar kann sie sich zusammen mit der Einsprache als Strafklägerin nachträglich konstituieren. Jedoch wird damit die Gewährung des Gehöranspruchs wie bei der beschuldigten Person zu einer Holschuld des Strafklägers. ${ }^{1}$ An dieser Stelle greife ich vor auf Kapitel 5, wo Oehen darauf hinweist, dass sich ein solches System mit Blick auf den Strafkläger nicht von vornherein als geschädigtenunfreundlich erweisen müsse. Solange die geschädigte Person umfassend über ihre Rechte informiert und ihr für die Geltendmachung ihrer Rechte genügend lange Fristen eingeräumt werden, sei gegen «die Gewährung von Verfahrensrechten nur auf Nachfrage hin» per se nichts einzuwenden (S. 149). Nach Oehen bleiben allerdings diese zwei Bedingungen gerade im Strafbefehlsverfahren unberücksichtigt. Daher ist das Strafbefehlsverfahren in seiner aktuellen Form nach Auffassung von Oehen mit

\footnotetext{
Vgl. Marc Thommen, Kurzer Prozess - fairer Prozess? Strafbefehls- und abgekürzte Verfahren zwischen Effizienz und Gerechtigkeit, Bern 2013, S. 79.
}

Blick auf den Strafkläger geschädigtenunfreundlich (S. 150).

7 Der Strafkläger im abgekürzten Verfahren bildet schliesslich Gegenstand von Kapitel 4. Einleitend hält Oehen fest, dass dem Strafkläger im abgekürzten Verfahren eine entscheidende Rolle zukomme, weil er die Anklageschrift ablehnen und damit das Verfahren zu Fall bringen könne. Dies sei Grund dafür, dass das abgekürzte Verfahren hauptsächlich bei «opferlosen» Delikten zur Anwendung gelange (S. 124). Trotz dieser Feststellung schliesst Oehen Kapitel 4 unter folgendem Titel: «Zusammenfassung: Randfigur im abgekürzten Verfahren». Oehen kommt zum Ergebnis, dass der Strafkläger im abgekürzten Verfahren trotz seines Vetorechts zur Anklageschrift nur marginal in Erscheinung trete (S. 144 ff.). Diese Feststellung trifft zu. Jedoch ist dabei zu beachten, dass das abgekürzte Verfahren in der Regel nur erfolgreich zum Abschluss kommt, wenn auch die Interessen des Strafklägers berücksichtigt worden sind, andernfalls der Strafkläger von seinem Vetorecht Gebrauch machen würde. Daher ist die Ausübung der übrigen Verfahrensrechte des Strafklägers von untergeordneter Bedeutung. ${ }^{2}$ Weiter führt Oehen aus, dass das abgekürzte Verfahren für den Strafkläger mit vielen Vorteilen verbunden ist, dennoch sei seine Stellung aber nicht so stark, wie dies in der Lehre teilweise vorgebracht werde (S. 146). Diese Schlussfolgerung sehe ich kritisch: Meiner Auffassung nach ist die Stellung des Strafklägers im abgekürzten Verfahren stark. Sie hängt jedoch massgeblich

2 Vgl. hierzu Christina Galeazzi, Der Zivilkläger im Strafbefehls- und im abgekürzten Verfahren, Zürich/Basel/Genf 2016, S. 148. 
davon ab, wie sehr sich die beschuldigte Person vom Strafkläger unter Druck setzen lässt. Je mehr der beschuldigten Person an der Durchführung des abgekürzten Verfahrens liegt, desto mehr wird sie darum bemüht sein, dass die Interessen des Strafklägers angemessen berücksichtigt werden. 3

Mit Kapitel 5 schliesst Oehen seine Untersuchungen und zieht - wie von ihm selbst in der Einleitung angekündigt Bilanz zum modernen Strafprozess und den Teilhabemöglichkeiten des Strafklägers. Das Strafbefehlsverfahren erfüllt die Anforderungen einer effizienten Verfahrensform. Dieses Ziel wird aber u.a. damit erreicht, dass geschädigte Personen an den Rand des Verfahrens, wenn nicht gar aus dem Verfahren gedrängt werden (S. 148 ff.). Anders sieht es beim abgekürzten Verfahren aus, welches aus Sicht des Strafklägers «tendenziell vorteilhaft» erscheint. Dagegen ist fraglich, inwiefern es als effizient bezeichnet werden kann (S. 151 ff.). Oehen schliesst mit folgendem Fazit: Das Strafbefehlsverfahren sei aus Sicht der geschädigten Person geprägt von «Effizienz statt Teilhabe». Umgekehrt sei die Situation im abgekürzten Verfahren, hier gelte «Teilhabe statt Effizienz».

9 Im Gegensatz zum Zivilkläger ist zum Strafkläger nur wenig bekannt. Daher ist es für die Praxis wie auch für die Wissenschaft umso wertvoller, dass sich Oehen in seiner Dissertation mit der Figur des Strafklägers und seinen Rechten auseinandersetzt. Insbesondere die detaillierten Erläuterungen zur Konstituierung und den einzelnen Verfahrensrechten des
Strafklägers liefern Praktikern wichtige und hilfreiche Hinweise.

10 Indes überzeugt die der Dissertation zu Grunde liegende Fragestellung nicht gänzlich. Denn mit der Verfahrensteilnahme des Strafklägers gehen in der Regel Verfahrensverzögerungen einher. Mit anderen Worten sind Effizienz und uneingeschränkte Verfahrensteilnahme des Strafklägers nicht gleichzeitig zu haben. Die Frage ist also vielmehr, wie mit diesem Dilemma umgegangen wird. In diesem Zusammenhang wären vertiefte Untersuchungen wünschenswert gewesen, weshalb die Figur des Strafklägers in die schweizerische Strafprozessordnung aufgenommen wurde.

11 Insgesamt leistet Oehens Dissertation jedoch einen wichtigen Beitrag zum Verständnis des Strafklägers.

«Der Strafkläger im Strafbefehls- und im abgekürzten Verfahren», Moritz Oehen, Carl Grossmann Verlag, Berlin/Bern, 2019, ISBN: 978-3-941159-32-7 (gedruckte Ausgabe, Hardcover), ISBN: 978-3941159-33-4 (e-Book, Open Access) 